\title{
Prevalence of diarrhoea, acute respiratory infections, and malaria over time (1995-2017): A regional analysis of 23 countries in West and Central Africa
}

\author{
Aline Simen-Kapeu ${ }^{1}$, \\ Lisa Bogler ${ }^{2}$, \\ Ann-Charline Weber' ${ }^{2}$, \\ John Ntambi ${ }^{1}$, \\ Noel Marie Zagre ${ }^{3}$, \\ Sebastian Vollmer' ${ }^{2}$, \\ Rene Ehounou Ekpini ${ }^{1}$ \\ ${ }^{1}$ United Nations Children's Fund \\ (UNICEF), West and Central \\ Africa Regional Office, Dakar, \\ Senegal \\ ${ }^{2}$ Department of Economics \\ and Centre for Modern Indian \\ Studies, University of Göttingen, \\ Göttingen, Germany \\ ${ }^{3}$ UNICEF Area Representative \\ for Gabon and São Tomé and \\ Príncipe and to the ECCAS, \\ Libreville, Gabon
}

\begin{abstract}
Backgound The global community recognizes the urgent need to end preventable child deaths, making it an essential part of the third Sustainable Development Goal. Pneumonia, diarrhoea, and malaria still remain the leading causes of deaths among children under five years, especially in one of the poorest geographic regions of the world - West and Central Africa. This region carries a disproportionately high share of the global burden, both in terms of morbidity and mortality. The study aims to assess levels and trends of the prevalence of these three childhood diseases in West and Central Africa to better inform ongoing and future programmes to improve child survival.

Methods Demographic and Health Surveys and Multiple Indicator Cluster Surveys available from 1995 to 2017 for 23 countries in West and Central Africa were analysed. We estimated the prevalence of diarrhoea, acute respiratory infections (ARI), malaria, and fever as a proxy for malaria, and split the data into three time periods to assess these trends in disease prevalence over time. Further analyses were done to assess the variations by geographic location (urban and rural) and gender (boys and girls).
\end{abstract}

Results In West and Central Africa, the reduction of the prevalence rates of diarrhoea, acute respiratory infections, malaria, and fever has decelerated over time (1995-2009), and little improvements occurred between 2010 and 2017. The reduction within the region has been uneven and the prevalence rates either increased or stagnated for diarrhoea (nine countries), ARI (four countries), and fever (six countries). The proportion of affected children was high in emergency or fragile settings. Disaggregated analyses of population-based data show persistent gaps between the prevalence of diseases by geographic location and gender, albeit not significant for the latter.

Conclusions Without intensified commitment to reducing the prevalence of pneumonia, malaria, and diarrhoea, many countries will not be able to meet the SDG goal to end preventable child deaths. Evidence-driven programmes that focus on improving equitable access to preventive health care information and services must be fostered, especially in complex emergency settings. This will be an opportunity to strengthen primary health care, including community health programmes, to achieve universal health coverage.

A high prevalence of preventable childhood diseases continues to burden many low- and middle-income countries [1,2]. Pneumonia, diarrhoea, and malaria still remain the leading causes of deaths among children; they were responsible for approximately one third of global deaths among children under five in 2018, totalling an estimated 1.6 million deaths in this age group $[3,4]$. This is shocking considering that many of these deaths are preventable by timely, low-cost and high-impact interventions [4]. 
The global community recognizes the urgent need to end preventable child deaths in all countries, making it an essential part of global child survival goals and strategies including the United Nations Global Strategy for Women's, Children's and Adolescents' Health (2016-2030) [5] and the Sustainable Development Goals (SDGs) [6]. Global health initiatives that translated into the Global Action Plan for the Prevention of Pneumonia and Diarrhoea (GAPPD) and the WHO Global Malaria Programme (GMP) strive towards a reduction in morbidity and mortality due to the three childhood diseases $[1,7]$. In great part due to such programmes and large-scale interventions, child mortality has been falling over the past decades [3,4] and so has the prevalence of childhood diseases [1,2]. However, progress is unequally distributed and slowing down [1,4].

Many countries in sub-Saharan Africa, especially in West and Central Africa (WCA), missed the Millennium Development Goals and are lagging far behind the SDGs targets of no more than 25 deaths per 1000 livebirths among under-five children [8]. The WCA region is facing numerous challenges including a shift in demographics (birth and death rates and patterns), rapid urbanization, population displacements, violent extremism, armed conflicts, insecurity and the succession of disease outbreaks. In addition, children have an increased likelihood of being exposed to multiple deprivations including poor access to health services, malnutrition, lack of access to clean water and basic sanitation facilities, other infections such as HIV, and overcrowded conditions and environmental contaminants like indoor and outdoor air pollution $[9,10]$. Over two-thirds of the global burden of pneumonia and diarrhoea mortality occurs in just 15 countries, and five of them are located in WCA including Nigeria, the Democratic Republic of the Congo, Chad, Niger, and Côte d'Ivoire [2]. Similarly, malaria continues to be a major cause of death for children, taking the life of a child every two minutes despite large investments in its reduction and despite the fact that the proportion of infected children has halved in endemic areas of Africa since 2000 [11]. The Democratic Republic of the Congo and Nigeria accounted for 84 million (54\%) of total malaria cases [1].

Monitoring trends in disease prevalence is important to inform ongoing and future programmes to combat these diseases. Many studies exist that estimate disease prevalence in individual countries at different points in time, including for malaria [12], pneumonia [13,14], and diarrhoea [15-17]. Meta-analyses review those single-country studies to estimate global trends in morbidity and mortality in single years [18-20] or over time [21]. We use nationally representative data from 23 countries in WCA to analyse levels and trends in childhood disease (pneumonia, diarrhoea, malaria) prevalence both for the entire region and separately for each country. The study focuses on morbidity instead of mortality as the disease prevalence captures the demand for prevention and treatment more accurately than the number of deaths. The study aims to inform governments and policy makers during programme development to accelerate child survival in sub-Saharan Africa.

\section{METHODS}

\section{Data}

In this paper, we combined two data sources, the Demographic and Health Surveys (DHS) and Multiple Indicator Cluster Surveys (MICS). The DHS is administered by ICF International. In seven rounds since 1984, the DHS Program has collected nationally representative data in low- and middle-income countries. MICS is a data collection initiative by UNICEF and has collected data on women and children in low- and middle-income countries since 1995. In both surveys, women in reproductive age, typically between 15 and 49, were asked for information on all children ever born to them. The surveys apply a multistage stratified sampling design for the within-country selection of households. For each country, regions were defined, within which the population was stratified into urban and rural. For each stratified area, enumeration areas were randomly drawn and denoted as primary sampling units (PSUs). Selection of PSUs was based on a probability proportional to size, in this case the number of households. Within each PSU, all households were listed from the most recent population census. Applying an equal probability of systematic sampling, a fixed number of households in each PSU was selected for an interview. Weights for the calculation of nationally representative statistics are provided with the survey data. For the analysis across countries, we re-scaled weights using each country's female population aged 15 to 49 years in the last year of the respective time period. This ensures that small countries do not excessively influence the estimation of overall disease prevalence.

In this analysis, we included data from 1995 to 2017 for all countries in WCA for which data was available.

\section{Outcomes}

We analysed trends of the three childhood diseases diarrhoea, acute respiratory infections (ARI) as proxy for pneumonia, malaria, and fever as a proxy for malaria. All diseases were coded as dummy variables that equal one if the child had the disease. A child was defined as having diarrhoea or fever if his/her guardian responded 
that the child suffered from diarrhoea or fever in the past 24 hours. Malaria was identified by a positive result of the rapid diagnostic test. A child was defined as having ARI if he/she had cough in the past 24 hours and experienced short, rapid breathing. A stricter definition would identify the disease as ARI only if the breathing difficulties were related to a problem in the chest. However, only more recent surveys included the question whether the child's difficulty in breathing was due to a problem in the chest or a blocked nose, which would result in fewer observations for the trend analysis. We looked at ARI as a proxy for pneumonia, despite evidence that it is not a very accurate indicator $[22,23]$. Unfortunately, the DHS and MICS do not contain more accurate data on pneumonia such as diagnostic tests.

\section{Statistical analysis}

In order to assess trends in disease prevalence over time, we split the data into three time periods. Time periods were defined such that each country had at least one survey in each time period, as far as possible. This resulted in the earliest period containing surveys between 1995 and 2001, the middle period containing surveys between 2002 and 2009, and the most recent time period containing surveys between 2010 and 2017. In the following, we refer to these time periods as the early, mid, and most recent time period. Since rapid tests for identifying malaria were only conducted in more recent surveys, malaria prevalence could only be shown for the recent time period.

First, we estimated the prevalence of each disease for all countries in the three time periods. We then repeated this exercise for rural and urban households separately, and for male and female children separately. To highlight heterogeneity between countries, we also calculated the prevalence of each disease separately for each country.

\section{RESULTS}

Our final samples included 100 surveys from 23 countries with data on diarrhoea, 99 surveys from 23 countries with data on ARI, 20 surveys from 12 countries with data on malaria, and 102 surveys from 23 countries with data on fever. The number of observations varied greatly between surveys.

Figure 1, Panel A depicts the changes over time in the prevalence of diarrhoea for all included countries. As can be observed, the decline was substantial between the first two study periods, 1995-2001 and 2002-2009,
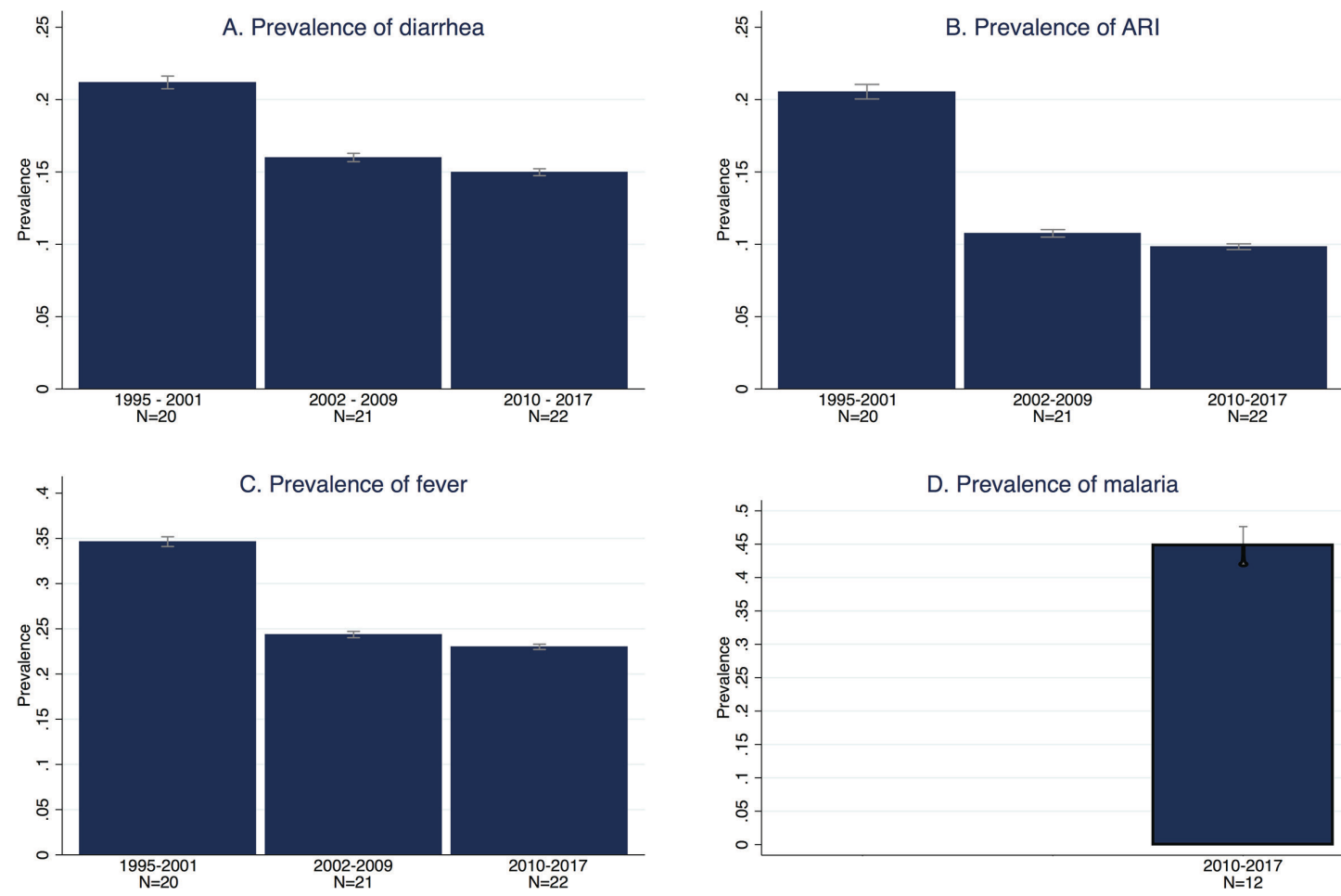

Figure 1. Prevalence of childhood diseases over time for all countries. Panel A. Prevalence of diarrhoea over time. Panel B. Prevalence of acute respiratory infections over time. Panel C. Prevalence of fever over time. Panel D. Prevalence of malaria. 
but stagnated between the mid period and the most recent period (2010-2017). The pooled prevalence of diarrhoea first decreased from $21.2 \%$ to $16.0 \%$, but remained at $15.0 \%$ in the most recent time period. Table 1 shows the differences across countries. The latest estimates per country ranged from $24 \%$ in the Central African Republic (95\% confidence interval $(\mathrm{CI})=23.0 \%-25.3 \%$ ) and Equatorial Guinea (95\% confidence interval $(C I)=21.7 \%-25.8 \%$ ) to $8 \%$ in Sierra Leone (95\% CI $=7.2 \%-8.6 \%$ ). Prevalence remained rather high with the majority of countries exhibiting rates higher than $15 \%$ and only few countries with a lower prevalence, namely Sierra Leone, Guinea with 10\% (95\% CI=9.2\%-11.6\%), Benin (95\% CI $10.0 \%-11.5 \%)$ and Nigeria (95\% CI =9.9\%-11.2\%) with 11\%, Ghana (95\% CI=10.7\%-13.4\%) and Guinea-Bissau (95\% CI=10.8\%$13.6 \%$ ) with $12 \%$, and Niger with $14 \%$ (95\% CI $=13.5 \%-15.4 \%)$. Similarly, within-country reduction in the prevalence rates among the first and last available surveys showed great variation. Diarrhoea prevalence decreased in all countries except for Senegal, Cameroon and Liberia who faced increased rates, and Chad and Gabon where rates remained the same. In contrast, large reductions were observed in Niger between 1998 and 2012 (25 percentage points), Sierra Leone between 2000 and 2017 (18 percentage points), Togo between 1998 and 2013 (16 percentage points) and Benin between 1996 and 2017 (15 percentage points). However, the time spans between the first and most recent surveys varied between countries which increased the observed heterogeneity in trends. Figure 2, Panel A presents the change in the prevalence of diarrhoea graphically. It illustrates the heterogeneity across countries as well as the trend of declining diarrhoea prevalence. In the Online Supplementary Document, figures for each country depict the trend in the prevalence of diarrhoea over time while taking into account the actual timing of each survey (Figure S5, similar for ARI and fever in Figure S6 and Figure S7).

Table 1. Prevalence of diarrhoea by country in first and most recent survey year

\begin{tabular}{|c|c|c|c|c|}
\hline COUNTRY & YEAR & Prevalence & $95 \% \mathrm{Cl}$ & OBSERVATIONS \\
\hline \multirow{2}{*}{ Benin } & 1996 & 0.26 & $0.241-0.285$ & 2721 \\
\hline & 2017 & 0.11 & $0.100-0.115$ & 12154 \\
\hline \multirow{2}{*}{ Burkina Faso } & 1998 & 0.20 & $0.188-0.221$ & 4922 \\
\hline & 2010 & 0.15 & $0.141-0.159$ & 13425 \\
\hline \multirow{2}{*}{ Cameroon } & 1998 & 0.19 & $0.173-0.215$ & 2054 \\
\hline & 2014 & 0.20 & $0.190-0.217$ & 6612 \\
\hline \multirow{2}{*}{$\begin{array}{l}\text { Central African } \\
\text { Republic }\end{array}$} & 2000 & 0.26 & $0.249-0.273$ & 12993 \\
\hline & 2010 & 0.24 & $0.230-0.253$ & 9994 \\
\hline \multirow{2}{*}{ Chad } & 1996 & 0.22 & $0.203-0.239$ & 6135 \\
\hline & 2014 & 0.22 & $0.212-0.238$ & 16405 \\
\hline \multirow{2}{*}{ Congo } & 2005 & 0.14 & $0.126-0.161$ & 4158 \\
\hline & 2014 & 0.18 & $0.166-0.188$ & 8557 \\
\hline \multirow{2}{*}{$\begin{array}{l}\text { Congo Democratic } \\
\text { Republic }\end{array}$} & 2001 & 0.22 & $0.209-0.238$ & 9838 \\
\hline & 2013 & 0.17 & $0.159-0.185$ & 16535 \\
\hline \multirow{2}{*}{ Cote d'Ivoire } & 1998 & 0.23 & $0.195-0.261$ & 1605 \\
\hline & 2016 & 0.16 & $0.145-0.167$ & 8463 \\
\hline \multirow{2}{*}{$\begin{array}{l}\text { Equatorial } \\
\text { Guinea }\end{array}$} & 2000 & 0.24 & $0.217-0.258$ & 2087 \\
\hline & & & & \\
\hline \multirow{2}{*}{ Gabon } & 2000 & 0.17 & $0.159-0.190$ & 3655 \\
\hline & 2012 & 0.17 & $0.157-0.189$ & 5145 \\
\hline \multirow{2}{*}{ Gambia } & 2000 & 0.22 & $0.199-0.233$ & 3357 \\
\hline & 2013 & 0.18 & $0.160-0.198$ & 7461 \\
\hline \multirow{2}{*}{ Ghana } & 1998 & 0.18 & $0.168-0.201$ & 2927 \\
\hline & 2014 & 0.12 & $0.107-0.134$ & 5406 \\
\hline
\end{tabular}

\begin{tabular}{|c|c|c|c|c|}
\hline COUNTRY & YEAR & Prevalencee & $95 \% \mathrm{Cl}$ & OBSERVATIONS \\
\hline \multirow{2}{*}{ Guinea } & 1999 & 0.22 & $0.205-0.232$ & 4814 \\
\hline & 2016 & 0.10 & $0.092-0.116$ & 6823 \\
\hline \multirow{2}{*}{ Guinea-Bissau } & 2006 & 0.13 & $0.117-0.141$ & 5061 \\
\hline & 2014 & 0.12 & $0.108-0.136$ & 7053 \\
\hline \multirow{2}{*}{ Liberia } & 2006 & 0.22 & $0.195-0.236$ & 4740 \\
\hline & 2013 & 0.23 & $0.214-0.250$ & 6462 \\
\hline \multirow{2}{*}{ Mali } & 1995 & 0.26 & $0.241-0.273$ & 5123 \\
\hline & 2015 & 0.15 & $0.138-0.159$ & 15233 \\
\hline \multirow{2}{*}{ Mauritania } & 2007 & 0.22 & $0.207-0.231$ & 8064 \\
\hline & 2015 & 0.20 & $0.182-0.210$ & 9944 \\
\hline \multirow{2}{*}{ Niger } & 1998 & 0.39 & $0.365-0.407$ & 4145 \\
\hline & 2012 & 0.14 & $0.135-0.154$ & 11256 \\
\hline \multirow{2}{*}{ Nigeria } & 1999 & 0.16 & $0.144-0.173$ & 3078 \\
\hline & 2013 & 0.11 & $0.099-0.112$ & 27538 \\
\hline \multirow{2}{*}{$\begin{array}{l}\text { São Tomé and } \\
\text { Príncipe }\end{array}$} & 2000 & 0.19 & $0.170-0.211$ & 1795 \\
\hline & 2014 & 0.18 & $0.159-0.206$ & 1905 \\
\hline \multirow{2}{*}{ Senegal } & 1997 & 0.16 & $0.145-0.168$ & 6372 \\
\hline & 2017 & 0.18 & $0.172-0.194$ & 11004 \\
\hline \multirow{2}{*}{ Sierra Leone } & 2000 & 0.26 & $0.242-0.281$ & 2279 \\
\hline & 2017 & 0.08 & $0.072-0.086$ & 10612 \\
\hline \multirow{2}{*}{ Togo } & 1998 & 0.31 & $0.292-0.334$ & 3836 \\
\hline & 2013 & 0.15 & $0.137-0.171$ & 6358 \\
\hline
\end{tabular}

$\mathrm{CI}$ - confidence interval

The overall trend of ARI among children is presented in Figure 1, Panel B and Figure 2, Panel B. The average prevalence in the region has decreased by half from $20.6 \%$ in the first period to $10.8 \%$ in the mid period and $9.8 \%$ in the most recent period. Most of the countries have experienced significant reductions apart from Congo and Gabon where the prevalence rates increased. Table 2 presents prevalence rates of ARI at the country level for the first and most recent surveys. For most countries in the recent period the prevalence rates are below or equal to 15\% while prevalence remained high in the Central African Republic with 29\% (95\% $\mathrm{CI}=27.7-31.0 \%)$, São Tomé and Príncipe with 25\% (95\% CI=22.1-28.0\%) and Cameroon with 17\% (95\% $\mathrm{CI}=15.6-18.6 \%)$. The largest reductions between the first and most recent surveys were found in Democratic 

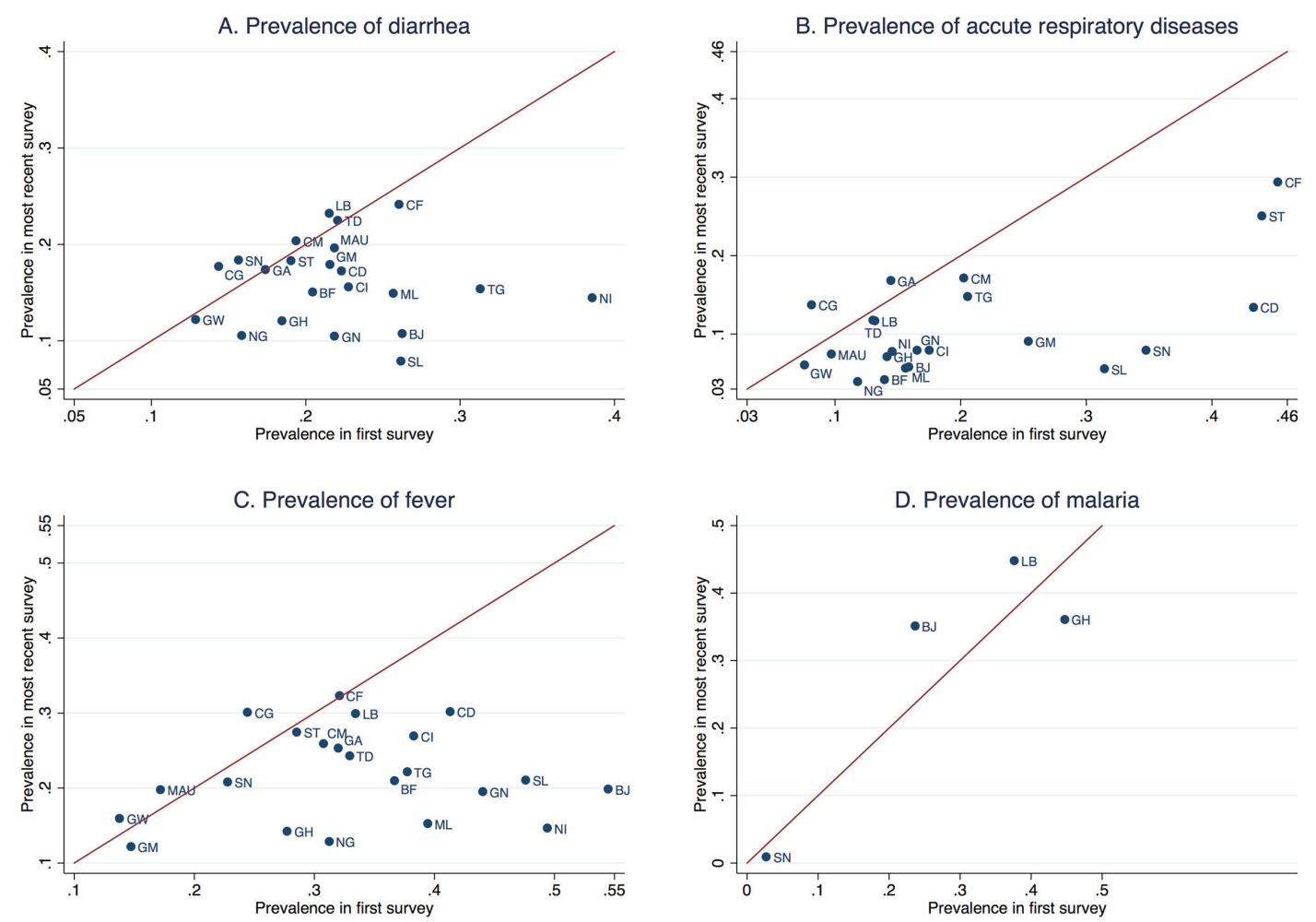

Figure 2. Change of prevalence of childhood diseases by country. Panel A. Change of prevalence of diarrhoea by country. Panel B. Change of prevalence of acute respiratory infections by country. Panel C. Change of prevalence of fever by country. Panel D. Change of prevalence of malaria by country.

Table 2. Prevalence of ARI by country in first and most recent survey year

\begin{tabular}{|c|c|c|c|c|}
\hline COUNTRY & YEAR & Prevalence & $95 \% \mathrm{Cl}$ & OBSERVATIONS \\
\hline \multirow{2}{*}{ Benin } & 1996 & 0.16 & $0.141-0.177$ & 2711 \\
\hline & 2017 & 0.06 & $0.052-0.064$ & 12173 \\
\hline \multirow{2}{*}{ Burkina Faso } & 1998 & 0.14 & $0.124-0.155$ & 4884 \\
\hline & 2010 & 0.04 & $0.036-0.048$ & 13409 \\
\hline \multirow{2}{*}{ Cameroon } & 1998 & 0.20 & $0.179-0.227$ & 2044 \\
\hline & 2014 & 0.17 & $0.156-0.186$ & 6607 \\
\hline \multirow{2}{*}{$\begin{array}{l}\text { Central African } \\
\text { Republic }\end{array}$} & 2000 & 0.45 & $0.432-0.474$ & 7480 \\
\hline & 2010 & 0.29 & $0.277-0.310$ & 9972 \\
\hline \multirow{2}{*}{ Chad } & 1996 & 0.13 & $0.116-0.145$ & 6116 \\
\hline & 2014 & 0.12 & $0.105-0.129$ & 16318 \\
\hline \multirow{2}{*}{ Congo } & 2005 & 0.08 & $0.068-0.095$ & 4064 \\
\hline & 2014 & 0.14 & $0.125-0.149$ & 8563 \\
\hline \multirow{2}{*}{$\begin{array}{l}\text { Congo Democratic } \\
\text { Republic }\end{array}$} & 2001 & 0.43 & $0.405-0.462$ & 4862 \\
\hline & 2013 & 0.13 & $0.118-0.150$ & 16512 \\
\hline \multirow{2}{*}{ Cote d'Ivoire } & 1998 & 0.18 & $0.152-0.198$ & 1597 \\
\hline & 2016 & 0.08 & $0.068-0.089$ & 8461 \\
\hline Equatorial & 2000 & 0.36 & $0.329-0.393$ & 1159 \\
\hline \multicolumn{5}{|l|}{ Guinea } \\
\hline \multirow{2}{*}{ Gabon } & 2000 & 0.14 & $0.129-0.160$ & 3648 \\
\hline & 2012 & 0.17 & $0.147-0.188$ & 5134 \\
\hline \multirow{2}{*}{ Gambia } & 2000 & 0.25 & $0.224-0.284$ & 1460 \\
\hline & 2013 & 0.09 & $0.077-0.104$ & 7431 \\
\hline \multirow{2}{*}{ Ghana } & 1998 & 0.14 & $0.126-0.157$ & 2920 \\
\hline & 2014 & 0.07 & $0.061-0.081$ & 5402 \\
\hline
\end{tabular}

\begin{tabular}{|c|c|c|c|c|}
\hline COUNTRY & YEAR & Prevalence & $95 \% \mathrm{Cl}$ & OBSERVATIONS \\
\hline \multirow{2}{*}{ Guinea } & 1999 & 0.17 & $0.153-0.179$ & 4803 \\
\hline & 2016 & 0.08 & $0.070-0.088$ & 6814 \\
\hline \multirow{2}{*}{ Guinea-Bissau } & 2006 & 0.08 & $0.065-0.086$ & 5057 \\
\hline & 2014 & 0.06 & $0.051-0.070$ & 7046 \\
\hline \multirow{2}{*}{ Liberia } & 2006 & 0.13 & $0.116-0.148$ & 4712 \\
\hline & 2013 & 0.12 & $0.100-0.133$ & 6453 \\
\hline \multirow{2}{*}{ Mali } & 1995 & 0.16 & $0.142-0.171$ & 5048 \\
\hline & 2015 & 0.06 & $0.049-0.063$ & 15238 \\
\hline \multirow{2}{*}{ Mauritania } & 2007 & 0.10 & $0.088-0.106$ & 8016 \\
\hline & 2015 & 0.07 & $0.064-0.084$ & 9894 \\
\hline \multirow{2}{*}{ Niger } & 1998 & 0.15 & $0.130-0.161$ & 4143 \\
\hline & 2012 & 0.08 & $0.067-0.088$ & 11201 \\
\hline \multirow{2}{*}{ Nigeria } & 1999 & 0.12 & $0.106-0.131$ & 3039 \\
\hline & 2013 & 0.04 & $0.035-0.043$ & 27422 \\
\hline \multirow{2}{*}{$\begin{array}{l}\text { São Tomé and } \\
\text { Príncipe }\end{array}$} & 2000 & 0.44 & $0.396-0.484$ & 712 \\
\hline & 2014 & 0.25 & $0.221-0.280$ & 1904 \\
\hline \multirow{2}{*}{ Senegal } & 2000 & 0.35 & $0.328-0.368$ & 4313 \\
\hline & 2017 & 0.08 & $0.071-0.087$ & 11005 \\
\hline \multirow{2}{*}{ Sierra Leone } & 2000 & 0.31 & $0.282-0.347$ & 1410 \\
\hline & 2017 & 0.06 & $0.049-0.062$ & 10648 \\
\hline \multirow{2}{*}{ Togo } & 1998 & 0.21 & $0.189-0.223$ & 3806 \\
\hline & 2013 & 0.15 & $0.132-0.163$ & 6350 \\
\hline
\end{tabular}

$\mathrm{CI}$ - confidence interval, ARI - acute respiratory infections

Republic of Congo between 2001 and 2013 (30 percentage points), Senegal between 2000 and 2017 (27 percentage points) and Sierra Leone between 2000 and 2017 (25 percentage points). In the case of Equatorial Guinea information was only available for the year 2000. 
Figure 1, Panel C depicts the change in the prevalence of fever for all included countries over time. Overall, fever prevalence decreased substantially. Rates declined from an average of $35.7 \%$ in the first study period (1995-2001) to $24.4 \%$ in the second period (2002-2009) and 23.0\% in the last period (2010-2017). Variations across countries are described in detail in Table 3, depicting similar rates in the last available surveys for each country, but identifying different patterns in the reduction over time (Figure 2, Panel C). Benin has achieved large improvements with a reduction of 35 percentage points in its prevalence rate between 1996 and 2017. Likewise, Sierra Leone (27 percentage points, 2000-2017), Guinea (25 percentage points, 1999 2016), Mali (24 percentage points, 1995-2015), Niger (34 percentage points, 1998-2012) and Nigeria (18 percentage points, 1999-2013) have shown a significant reduction across study periods. However, despite improvements, high levels of prevalence of fever persisted in some countries. This becomes clear when looking at prevalence levels in the Central African Republic with the highest rate of 32\% (95\% CI=30.8\%-33.7\%), Congo (95\% CI =28.4\%-31.7\%), Liberia (95\% CI =27.5\%-32.4\%), and Democratic Republic of Congo (95\% $\mathrm{CI}=28.4 \%-31.9 \%$ ) with rates of 30\%, Sao Tome and Principe (95\% CI $=24.7 \%-30.1 \%$ ) and Cote d'Ivoire (95\% $\mathrm{CI}=25.2 \%-28.5 \%$ ) with $27 \%$, and Cameroon with a rate of $26 \%$ (95\% CI $=24.4 \%-27.4 \%$ ).

Table 3. Prevalence of fever by country in first and most recent survey year

\begin{tabular}{|c|c|c|c|c|}
\hline COUNTRY & YEAR & Prevalence & $95 \% \mathrm{Cl}$ & OBSERVATIONS \\
\hline \multirow{2}{*}{ Benin } & 1996 & 0.55 & $0.523-0.568$ & 2713 \\
\hline & 2017 & 0.20 & $0.186-0.209$ & 12172 \\
\hline \multirow{2}{*}{ Burkina Faso } & 1998 & 0.37 & $0.347-0.387$ & 4913 \\
\hline & 2010 & 0.21 & $0.198-0.221$ & 13426 \\
\hline \multirow{2}{*}{ Cameroon } & 1998 & 0.31 & $0.278-0.338$ & 2046 \\
\hline & 2014 & 0.26 & $0.244-0.274$ & 6616 \\
\hline \multirow{2}{*}{$\begin{array}{l}\text { Central African } \\
\text { Republic }\end{array}$} & 2000 & 0.32 & $0.309-0.333$ & 13030 \\
\hline & 2010 & 0.32 & $0.308-0.337$ & 9983 \\
\hline \multirow{2}{*}{ Chad } & 1996 & 0.33 & $0.306-0.353$ & 6132 \\
\hline & 2014 & 0.24 & $0.226-0.260$ & 16405 \\
\hline \multirow{2}{*}{ Congo } & 2005 & 0.24 & $0.224-0.265$ & 4161 \\
\hline & 2014 & 0.30 & $0.284-0.317$ & 8561 \\
\hline \multirow{2}{*}{$\begin{array}{l}\text { Congo Democratic } \\
\text { Republic }\end{array}$} & 2001 & 0.41 & $0.392-0.434$ & 9848 \\
\hline & 2013 & 0.30 & $0.284-0.319$ & 16536 \\
\hline \multirow{2}{*}{ Cote d'Ivoire } & 1998 & 0.38 & $0.351-0.416$ & 1601 \\
\hline & 2016 & 0.27 & $0.252-0.285$ & 8466 \\
\hline \multirow{2}{*}{$\begin{array}{l}\text { Equatorial } \\
\text { Guinea }\end{array}$} & 2000 & 0.30 & $0.278-0.325$ & 2080 \\
\hline & & & & \\
\hline \multirow{2}{*}{ Gabon } & 2000 & 0.32 & $0.299-0.341$ & 3646 \\
\hline & 2012 & 0.25 & $0.228-0.278$ & 5147 \\
\hline \multirow{2}{*}{ Gambia } & 2000 & 0.15 & $0.126-0.169$ & 3352 \\
\hline & 2013 & 0.12 & $0.106-0.137$ & 7454 \\
\hline \multirow{2}{*}{ Ghana } & 1998 & 0.28 & $0.258-0.298$ & 2918 \\
\hline & 2014 & 0.14 & $0.126-0.158$ & 5406 \\
\hline
\end{tabular}

\begin{tabular}{|c|c|c|c|c|}
\hline COUNTRY & YEAR & PREVALENCE & $95 \% \mathrm{Cl}$ & OBSERVATIONS \\
\hline \multirow{2}{*}{ Guinea } & 1999 & 0.44 & $0.422-0.459$ & 4752 \\
\hline & 2016 & 0.19 & $0.179-0.210$ & 6824 \\
\hline \multirow{2}{*}{ Guinea-Bissau } & 2006 & 0.14 & $0.126-0.151$ & 5066 \\
\hline & 2014 & 0.16 & $0.148-0.170$ & 7051 \\
\hline \multirow{2}{*}{ Liberia } & 2006 & 0.33 & $0.314-0.355$ & 4725 \\
\hline & 2013 & 0.30 & $0.275-0.324$ & 6460 \\
\hline \multirow{2}{*}{ Mali } & 1995 & 0.39 & $0.375-0.414$ & 5117 \\
\hline & 2015 & 0.15 & $0.142-0.161$ & 15250 \\
\hline \multirow{2}{*}{ Mauritania } & 2007 & 0.17 & $0.159-0.185$ & 8049 \\
\hline & 2015 & 0.20 & $0.182-0.213$ & 9917 \\
\hline \multirow{2}{*}{ Niger } & 1998 & 0.49 & $0.473-0.515$ & 4145 \\
\hline & 2012 & 0.15 & $0.135-0.157$ & 11245 \\
\hline \multirow{2}{*}{ Nigeria } & 1999 & 0.31 & $0.293-0.332$ & 3078 \\
\hline & 2013 & 0.13 & $0.121-0.136$ & 27491 \\
\hline \multirow{2}{*}{$\begin{array}{l}\text { São Tomé and } \\
\text { Príncipe }\end{array}$} & 2000 & 0.29 & $0.258-0.313$ & 1792 \\
\hline & 2014 & 0.27 & $0.247-0.301$ & 1869 \\
\hline \multirow{2}{*}{ Senegal } & 2000 & 0.23 & $0.212-0.244$ & 8121 \\
\hline & 2017 & 0.21 & $0.195-0.221$ & 11005 \\
\hline \multirow{2}{*}{ Sierra Leone } & 2000 & 0.48 & $0.451-0.501$ & 2278 \\
\hline & 2017 & 0.21 & $0.199-0.222$ & 10632 \\
\hline \multirow{2}{*}{ Togo } & 1998 & 0.38 & $0.353-0.402$ & 3816 \\
\hline & 2013 & 0.22 & $0.203-0.239$ & 6358 \\
\hline
\end{tabular}

CI - confidence interval

Table 4. Prevalence of malaria by country in most recent survey year

\begin{tabular}{lcccc} 
& Year & Prevalence & 95\% Cl & Observations \\
Benin & 2017 & 0.35 & $0.328-0.374$ & 5558 \\
\hline Burkina Faso & 2010 & 0.76 & $0.745-0.777$ & 5724 \\
\hline $\begin{array}{l}\text { Congo Democratic } \\
\text { Republic }\end{array}$ & 2013 & 0.30 & $0.271-0.328$ & 7276 \\
\hline Cote d'Ivoire & 2011 & 0.41 & $0.373-0.443$ & 2864 \\
\hline Gambia & 2013 & 0.02 & $0.011-0.034$ & 2703 \\
\hline Ghana & 2014 & 0.36 & $0.326-0.396$ & 2373 \\
\hline Guinea & 2012 & 0.47 & $0.428-0.505$ & 2775 \\
\hline Liberia & 2011 & 0.45 & $0.411-0.485$ & 2426 \\
\hline Mali & 2012 & 0.47 & $0.434-0.497$ & 4182 \\
\hline Nigeria & 2010 & 0.51 & $0.464-0.554$ & 4352 \\
\hline Senegal & 2017 & 0.01 & $0.005-0.013$ & 9483 \\
\hline Togo & 2013 & 0.37 & $0.338-0.406$ & 2870 \\
\hline
\end{tabular}

The rapid test for malaria was implemented only in recent surveys and the information available covers a total of 12 countries (Table 4, Figure 1, Panel D, Figure 2, Panel D). Table 4 shows malaria prevalence from the last available surveys at the country level. Burkina Faso had the highest prevalence rate of $76 \%$ (95\% $\mathrm{CI}=74.5 \%-77.7 \%)$ followed by Nigeria with $51 \%$ (95\% CI=46.4\%-55.4\%), Mali with $47 \%$ (95\% CI $=43.4 \%-49.7 \%$ ), Guinea with $47 \%$ (95\% CI $=42.8 \%$ $50.5 \%)$, Liberia with $45 \%(95 \% \mathrm{CI}=41.1 \%-48.5 \%)$ and Cote d'Ivoire with $41 \%$ (95\% CI=37.3\%-44.3\%). At the other extreme, Senegal and Gambia had a prevalence rate of 1 (95\% $\mathrm{CI}=0.5 \%-1.3 \%)$ and $2 \%(95 \% \mathrm{CI}=1.1 \%-3.4 \%)$, respectively.

In order to facilitate policy recommendations regarding targeting of health programmes, we disaggregated these overall prevalences by location (rural/urban) and gender. Graphs 
depicting the results are presented in Figures S1 to S4 in the Online Supplementary Document). Children in households located in rural areas had a higher prevalence of all childhood diseases analysed. The gap between the prevalence by location decreased only slightly since 1995. Girls had a lower prevalence of diarrhoea and to a lesser extent a lower prevalence of ARI and fever, although this difference is not statistically significant. The gap between the prevalence by gender neither decreased nor increased significantly since 1995 .

\section{DISCUSSION}

This study was conducted to assess levels and trends of the prevalence of childhood diseases during the past 25 years in WCA and with the aim of contributing to fill the literature gap between country-specific studies and global analyses of the prevalence and trends of those diseases. Our analysis found important progress in the reduction of the prevalence of diarrhoea, ARI, malaria, and fever in the pooled sample of countries between the periods 1995 and 2009. However, given the international attention placed on health in the SDGs, it is somewhat disheartening to see that relatively little progress was made at the aggregate level in the WCA region in the latest period 2010-2017.

These results highlight the proportion of the vulnerable populations, children under 5 years, affected by the three diseases in WCA, a particularly important region which includes countries with the highest prevalence rates worldwide, where these diseases are still an important contributor to the prevailing high levels of child mortality [3]. Prevalence rates continue to be high: $20 \%$ of children or more had diarrhoea in nine countries; at least $12 \%$ of children had symptoms of ARI in nine countries; the prevalence of fever was between $20 \%$ and $32 \%$ in 15 countries; and at least one third of children were tested positive for malaria in 10 countries. The three major killers of children under 5, pneumonia, malaria, and diarrhoea, can be addressed by highly effective and low cost preventive and therapeutic interventions, such as breastfeeding promotion, and Haemophilus influenzae type $b$ and pneumococcal vaccines for pneumonia, improved water and sanitation, rotavirus vaccine, zinc supplementation, oral rehydration solutions, and integrated community case management of childhood illnesses, and insecticide treated bednets, intermittent preventive treatment in pregnancy, and artemisinin-based combination therapy for malaria [1,7].

The slowdown in the decline of prevalence rates might indicate diminishing returns of the traditional investments on health. Thus, it calls for more concerted efforts and the combination of different strategies to accelerate the progress in reducing the prevalence of childhood diseases. Weak health systems (including community health systems) in low-income countries pose a barrier to acquire adequate information, knowledge, and care, especially for the most vulnerable populations [24]. The need for appropriate culturally sensitive education and awareness provided to the communities to considerably reduce the number of children likely to get affected by the three diseases is more vital than ever before. Empowerment of women and removing barriers to access care may help inculcate healthy practices among children under 5, and their mothers, fathers, and caregivers [25]. Similarly, as parasite resistance to antimalarial medicines emerges, new treatments have to be developed and made available for affected populations.

Disaggregated analyses of population-based data show persistent gaps between the prevalence of diseases by location (urban and rural) and gender (boys and girls), albeit not significant for the latter. Protecting every child's right requires addressing persistent inequities and disparities as no child should be left behind. As populations at risk grew, the average level of funding available per person at risk declined between 2012 and 2017 [1]. As jointly stated by all parties in the Astana Declaration in 2018 [26], considerable investments in strengthening primary health care, including community health programmes, is highly needed, to ensure that every child has access to preventive, promotional, and curative lifesaving interventions [5]. At the Global Forum on Pneumonia, organized by UNICEF, Save The Children, and partners in Barcelona in January 2020, all countries committed to accelerate progress by strengthening preventive health care services. Such initiatives are an important step and need to be translated into tangible actions.

The study further extends the literature by depicting within-region patterns that allow us to identify the fastest and slowest performing countries in the reduction of the prevalence of each specific disease. We noted an increase (Cameroon, Congo, Liberia, Senegal) or no change (Chad, and Gabon) in diarrhoea prevalence rates. ARI prevalence rates increased or stagnated in four countries (Chad, Congo, Gabon, and Liberia) and reduced in others. Fever prevalence rates reduced by at least 50\% in seven countries but limited or no change in Central African Republic, Gambia, Liberia, São Tomé and Príncipe, and Senegal. While the progress made is likely to be driven to a large extent by major global initiatives, the country heterogeneities highlight that the same strategy does not work equally well in each context. This heterogeneity could be attributed to the country-spe- 
cific context (including emergency settings) and differences in socio-economic and sociocultural practices. It could also be due to the methodological variation in the assessment of prevalence at the time of the survey.

Our study has several limitations. Information on diarrhoea, ARI, and fever is collected by asking the guardian about the child's past diseases. This might not capture the disease accurately. Especially the definition of ARI does not serve as a very accurate indicator of pneumonia, which is a main cause of child mortality $[22,23]$. Unfortunately, DHS and MICS only contain medical tests for malaria and even this test is only conducted in selected surveys. Fever, while it is one symptom of malaria, is a rather inaccurate proxy for malaria, as it is a symptom of other diseases such as pneumonia as well. Data availability therefore greatly limits our analysis. Furthermore, the study is descriptive and does not provide an analysis of drivers of the trends in prevalence rates.

Despite these constraints, this study lays out potential areas of improvement in the current sources of information and data collection instances that will facilitate research on the progress towards the reduction of childhood illnesses. At the same time, it outlines potential areas of research, such as the identification of the factors that might explain the heterogeneity across countries in the region and the reasons behind the slowdown in the reduction of the prevalence rates of each disease observed between 2010 and 2017.

\section{CONCLUSION}

Diarrhoea, acute respiratory infections, malaria, and fever are still highly prevalent in West and Central Africa. The reduction of these prevalence rates has decelerated over time (1995-2009), and little improvements occurred between 2010 and 2017. The large heterogeneity across countries and the over-representation of particular countries among those with the greatest prevalence rates in the region call for a renewed focus on high-burden countries and more analytical work to document and disseminate best practices of best-performing countries in terms of prevalence reduction. The speeding up in the achievement of global targets must be fostered, especially in complex emergency settings, by evidence-driven programmes that focus on improving access to preventive health care information and services. This will be an opportunity to strengthen primary health care to achieve universal health coverage. Without intensified commitment to reducing the prevalence of pneumonia, malaria, and diarrhoea, many countries will not be able to meet the SDG goal to end preventable child deaths.

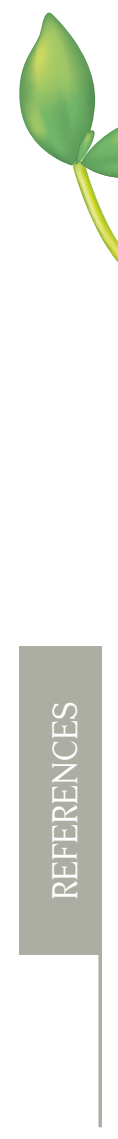

Funding: The study was funded by UNICEF West and Central Africa Regional Office in Dakar, Senegal in collaboration with Le Fonds Français Muskoka.

Authorship contributions: ASK, NMZ, LB, ACW and SV contributed to the conception and development of the paper as well as the literature review. LB and ACW conducted the data analysis, with support from SV who coordinated all studies and analyses. LB, ACW, ASK drafted the paper and JN, NMZ, REE, and SV provided critical feedback to the manuscript structure and contents. All authors contributed to the interpretation of the results and in revising and finalizing of the article and approved the final version of the manuscript.

Competing interests: The authors completed the ICMJE Unified Competing Interest form (available from convey.org) and declare no conflicts of interest.

\section{Additional material}

Online Supplementary Document

1 World Health Organization. World Malaria Report 2019. Geneva: World Health Organization; 2019. Available: https://www. who.int/publications-detail/world-malaria-report-2019. Accessed: 23 May 2020.

2 International Vaccine Access Center (IVAC). Pneumonia and diarrhea progress report: Driving progress through equitable investment and action. Baltimore, MD: Johns Hopkins Bloomberg School of Public Health; 2017. Available: https://www.jhsph. edu/ivac/wp-content/uploads/2018/04/IVAC-2017-Pneumonia-Diarrhea-Progress-Report-2.pdf. Accessed: 20 May 2020.

3 Liu L, Oza S, Hogan D, Chu Y, Perin J, Zhu J, et al. Global, regional, and national causes of under-5 mortality in 2000-15: an updated systematic analysis with implications for the Sustainable Development Goals. Lancet. 2016;388:3027-35. Medline:27839855 doi:10.1016/S0140-6736(16)31593-8

4 UN Inter-agency Groups for Child Mortality Estimation. Levels and trends in child mortality. Report 2019. Geneva: UNICEF; 2019.

5 The Global Strategy for women's and children's, and adolescents' health 2016-2030: survive, thrive, transform. Available: http://www.everywomaneverychild.org/wp-content/uploads/2017/10/EWEC_GSUpdate_Full_EN_2017_web-1.pdf. Accessed: 25 May 2020. 
6 UN General Assembly. Transforming our world: the 2030 Agenda for Sustainable Development, 21 October 2015, A/RES/70/1. Available: https://www.refworld.org/docid/57b6e3e44.html. Accessed: 25 May 2020.

7 World Health Organization. UNICEF. Ending Preventable Child Deaths from Pneumonia and Diarrhoea by 2025: The integrated Global Action Plan for Pneumonia and Diarrhoea (GAPPD). Geneva: WHO; 2013.

8 Countdown to 2030, 2017 Report. Available: https://www.countdown2030.org/reports-and-publications/countdown-2017-report. Accessed: 25 May 2020.

9 Every Child's right to survive: An agenda to end pneumonia deaths. United Nations Children's Fund (UNICEF) 2020. Available: https://www.unicef.org/reports/every-childs-right-survive-pneumonia-2020. Accessed: 25 May 2020.

10 UNICEF. One is too many: Ending child deaths from pneumonia and diarrhoea. Available: https://www.unicef.org/publications/files/UNICEF-Pneumonia-Diarrhoea-report-2016-web-version5.pdf. Accessed: 25 May 2020.

11 Cibulskis RE, Alonso P, Aponte J, Aregawi M, Barrette A, Bergeron L, et al. Malaria: Global progress 2000 - 2015 and future challenges. Infect Dis Poverty. 2016;5:61. Medline:27282148 doi:10.1186/s40249-016-0151-8

12 Mfueni E, Devleesschauwer B, Rosas-Aguirre A, Van Malderen C, Brandt PT, Ogutu B, et al. True malaria prevalence in children under five: Bayesian estimation using data of malaria household surveys from three sub-Saharan countries. Malar J. 2018;17:65. Medline:29402268 doi:10.1186/s12936-018-2211-y

13 Jordan HT, Prapasiri P, Areerat P, Anand S, Clague B, Sutthirattana S, et al. A comparison of population-based pneumonia surveillance and health-seeking behavior in two provinces in rural Thailand. Int J Infect Dis. 2009;13:355-61. Medline:18977679 doi:10.1016/j.ijid.2008.07.014

14 Williams BG, Gouws E, Boschi-Pinto C, Bryce J, Dye C. Estimates of world-wide distribution of child deaths from acute respiratory infections. Lancet Infect Dis. 2002;2:25-32. Medline:11892493 doi:10.1016/S1473-3099(01)00170-0

15 Berhe H, Mihret A, Yitayih G. Prevalence of diarrhea and associated factors among children under-five years of age in enderta woreda, Tigray, northern Ethiopia, 2014. Int J Ther Appl. 2016;31:32-7.

16 Diouf K, Tabatabai P, Rudolph J, Marx M. Diarrhoea prevalence in children under five years of age in rural Burundi: an assessment of social and behavioural factors at the household level. Glob Health Action. 2014;7:24895. Medline:25150028 doi:10.3402/gha.v7.24895

17 Målqvist M, Singh C, Kc A. Care seeking for children with fever/cough or diarrhoea in Nepal: equity trends over the last 15 years. Scand J Public Health. 2017;45:195-201. Medline:28078948 doi:10.1177/1403494816685342

18 Ayede AI, Kirolos A, Fowobaje KR, Williams LJ, Bakare AA, Oyewole OB, et al. A prospective validation study in South-West Nigeria on caregiver report of childhood pneumonia and antibiotic treatment using Demographic and Health Survey (DHS) and Multiple Indicator Cluster Survey (MICS) questions. J Glob Health. 2018;8:020806. Medline:30254744 doi:10.7189/ jogh.08.020806

19 Campbell H, el Arifeen S, Hazir T, O’Kelly J, Bryce J, Rudan I, et al. Measuring Coverage in MNCH: Challenges in Monitoring the Proportion of Young Children with Pneumonia Who Receive Antibiotic Treatment. PLoS Med. 2013;10:e1001421. Medline:23667338 doi:10.1371/journal.pmed.1001421

20 Rudan I, O’Brien KL, Nair H, Liu L, Theodoratou E, Qazi S, et al. Epidemiology and etiology of childhood pneumonia in 2010: estimates of incidence, severe morbidity, mortality, underlying risk factors and causative pathogens for 192 countries. J Glob Health. 2013;3:010401. Medline:23826505

21 Rudan I, Tomaskovic L, Boschi-Pinto C, Campbell H. Global estimate of the incidence of clinical pneumonia among children under five years of age. Bull World Health Organ. 2004;82:895-903. Medline:15654403

22 Walker CL, Rudan I, Liu L, Nair H, Theodoratou E, Bhutta ZA, et al. Global burden of childhood pneumonia and diarrhoea. Lancet. 2013;381:1405-16. Medline:23582727 doi:10.1016/S0140-6736(13)60222-6

23 Fischer Walker CL, Perin J, Aryee MJ, Boschi-Pinto C, Black RE. Diarrhea incidence in low- and middle-income countries in 1990 and 2010: a systematic review. BMC Public Health. 2012;12:220. Medline:22436130 doi:10.1186/1471-2458-12-220

24 McAllister DA, Liu L, Shi T, Chu Y, Reed C, Burrows J, et al. Global, regional, and national estimates of pneumonia morbidity and mortality in children younger than 5 years between 2000 and 2015: a systematic analysis. Lancet Glob Health. 2019; 7:e47-e57. Medline:30497986 doi:10.1016/S2214-109X(18)30408-X

25 Breaking barriers towards more gender-responsive and equitable health systems. World Health Organization Report, 2019. Available: https://www.who.int/healthinfo/universal_health_coverage/report/gender_gmr_2019.pdf?ua=1. Accessed 23 May 2020.

26 Astana Declaration on Primary Health Care, World Health Organization. Available: https://www.who.int/docs/default-source/ primary-health/declaration/gcphc-declaration.pdf. Accessed: 23 May 2020. 